\title{
Atividades Musicais Interativas como Instrumento Humanizador para Redução do Estresse de Crianças Submetidas a Cirurgias Urológicas
}

\author{
Lima, Veronique de Oliveira; Domenice, Sorahia; Costa, Elaine M Frade; Brito, \\ Vinicius N; Inácio, Marlene; Mendonça, Berenice B. \\ Serviço de Endocrinologia da Disciplina de Endocrinologia da FMUSP — veroniquelima@ig.com.br
}

Introdução Os hospitais por serem associados à dor e à doença tendem a ser locais hostilizados pela criança, principalmente quando há necessidade de procedimentos cirúrgicos. Não só o adoecer, mas também a internação é um fator que provoca emoções e sentimentos dolorosos . a redução do estresse nas crianças internadas aumenta a chance de maior aceitação do tratamento e reduz o impacto negativo no desenvolvimento global destas. Objetivos Humanizar o ambiente hospitalar, promovendo atividades musicais interativas durante o período de internação para cirurgia, para reduzir o estresse e a ansiedade de crianças, contribuindo para seu bem-estar. Métodos Todos os participantes do estudo, crianças e responsáveis, assinaram os termos de assentimento e consentimento livre e esclarecido, respectivamente. Participaram 39 pacientes, com idade de 6 a 14 anos, com internações programadas para correção de anormalidades urológicas, 20 delas no grupo experimental, participante das sessões musicais, e 19 no grupo controle, não participante das sessões. As atividades musicais foram ministradas diariamente pela pesquisadora, do pré-cirúrgico até, no máximo, o quinto dia após a cirurgia, com 15 a 30 minutos de duração. As atividades tinham caráter lúdico, envolvendo o ouvir, tocar, cantar e improvisar e foram utilizados um teclado, pequenos instrumentos musicais, aparelho de som, livros e fantoches. para avaliação do estresse foi utilizada a Escala de Stress Infantil-ESI, de Lipp \& Lucarelli no primeiro dia de internação e, no máximo, no quinto dia após a cirurgia. Os resultados dos testes foram avaliados pelo teste t-Student e os resultados estão expressos em média e DP, considerando-se significativos valores de $p<0,05$. Os participantes do grupo experimental responderam também à questionários sobre as atividades musicais. Resultados Não observamos diferença estatisticamente significante entre os valores de estresse inicial no grupo controle versus grupo experimental $(28,05 \pm 12,80$ versus $34,45 \pm 16,12 p>0,05)$. na comparação dos valores de estresse antes e após procedimento cirúrgico dentro do mesmo grupo observamos diferença estatisticamente significante na redução do grau de estresse no grupo experimental $(34,45 \pm 16,12$ versus $24,20 \pm 11,93, p<0,05)$ enquanto que o grupo controle manteve o mesmo nível de estresse inicial $(28,05 \pm 12,80$ versus $24,47 \pm 14,50$, $p>0,05)$. na resposta ao questionários todos os pais e crianças afirmaram que as atividades musicais foram importantes para maior aceitação da internação. Conclusões Observamos um efeito positivo das atividades musicais interativas na redução do estresse durante período de internação hospitalar em crianças portadoras de anormalidades urológicas, indicando que estes procedimentos, relativamente simples, podem contribuir para a humanização e melhor tolerância das crianças ao ambiente hospitalar.

Lima, Veronique de Oliveira; Domenice, Sorahia; Costa, Elaine M Frade; Brito, Vinicius N; Inácio, Marlene; Mendonça Berenice B. Atividades Musicais Interativas como Instrumento Humanizador para Redução do Estresse de Crianças Submetidas a Cirurgias Urológicas.. In: Anais do Congresso Internacional de Humanidades \& Humanização em Saúde [= Blucher Medical Proceedings, num.2, vol.1]. São Paulo: Editora Blucher, 2014. ISSN 2357-7282 DOI 10.5151/medpro-cihhs-10329 